\title{
The importance of the biochemical markers in rapid diagnosis and treatment of crushing syndrome
}

\author{
Iulian Constantin CREANGA ${ }^{1,2}$, Alexandra TOTAN², Iulia-loana STANESCU ${ }^{3}$, \\ Daniela MIRICESCU², Maria GREABU ${ }^{2}$ \\ 1"Prof. Dr. Dimitrie Gerota" Emergency Hospital, Bucharest, Romania \\ 2Department of Biochemistry, Faculty of Dental Medicine, "Carol Davila" University of Medicine and \\ Pharmacy, Bucharest, Romania \\ ${ }^{3}$ Department of Physiology, Faculty of Dental Medicine, "Carol Davila" University of Medicine and \\ Pharmacy, Bucharest, Romania
}

\begin{abstract}
Crushing represents the mechanism by which a group of skeletal muscles is caught by a high-energy traumatic agent over a wide area. The traumatic agent acts straight on the human body, causing serious injury, with potentially irreversible results. In the absence of a quick and correct treatment, these effects may lead to the death of the patient.

In this article we discuss the importance of local and general clinical examination for assessing the patient who was a victim of trauma with a high energy traumatic agent or had a surgical approach that could had caused damage to surrounding muscle tissue. The types of muscle damage in crush syndrome consist in partial torn of muscle, stretches or even transects of the affected muscles. The screening of biochemical markers in crush syndrome and their monitoring in dynamics provide an overview of the overall prognosis.
\end{abstract}

Keywords: crush syndrome, biochemical markers, creatine kinase, fibrinogen, LDH

\section{INTRODUCTION}

Crush syndrome (CS) is a serious medical condition that can be encountered in patients from emergency departments as a result of accidents occurring in different situations, including vehicle entrapment, falling debris (for example to construction workers), industrial accidents (mine accidents), natural disasters such as earthquakes or by prolonged pressure to a part of the body due to their own body weight in an immobile victim [1-4].
The energy absorbed by the affected area represents the difference between the energy of the traumatic agent and the resistance of the structure involved. The muscle is directly affected by the destruction of the muscle fibers, and, indirectly, by affecting the local circulation and disturbing the cellular metabolism, with the release of toxic products at both local and systemic levels (disturbing the membrane pump) [1-4].

Rhabdomyolysis is the most serious effect produced by crushing syndrome. The local metabo- 
lism becomes anaerobic, with the occurrence of glycolysis, lactic acid and lactic acidosis [1-4].

Rhabdomyolysis, literally meaning the breakdown of muscle tissue, can occur in a variety of other situations, all having a common pathophysiologic pathway which ends with the dispersing of muscle tissue content into the circulation. As a result of muscular compression, myocytes are damaged, and their intracellular constituents that include electrolytes, purines, enzymes (such as creatine kinase) and myoglobin are released into the extracellular fluid and blood circulation, resulting in a disruption of the body's homeostasis characterized by hyperkalemia, metabolic acidosis, hypovolemia, electrolyte imbalance, myoglobinuria etc. Severe secondary systemic pathological changes appear after muscular destruction that lead to several complications (e.g. arrhythmias, electrolyte abnormalities, acute renal injury, acidosis, volume depletion, compartment syndrome and disseminated intravascular coagulation). Acute kidney failure is the most common systemic complication of rhabdomyolysis for CS patients. At present, CS still has a high mortality. According to $\mathrm{Xu}$ et al [1], the pathophysiologic mechanism that leads to high mortality is represented by the ischemia/reperfusion (I/R) induced rhabdomyolysis and subsequent systemic inflammation mediated oxidative stress [1-4].

\section{AIM}

The purpose of this study is to analyze the involvement of biochemical markers used in current medical practice (creatine kinase - CK, lactate dehydrogenase - LDH, fibrinogen), in order to improve the rapid diagnostic protocols for crushing syndrome. We also intend to discuss the develop- ment of this type of screening taking into account the high specificity of biochemical marker described in the literature, such as ALD (aldolase).

In support of our point of view and to emphasize the importance of rapid diagnosis and the early establishment of local and general treatment we will present some clinical cases that our medical team treated during the years.

\section{MATERIALS AND METHODS}

The signs and symptoms were observed and registered while the patients were admitted in the emergency room. Radiology (Rx), computer tomography (CT) and laboratory tests were used for the diagnosis. The CK and LDH levels were determined by spectrophotometry with ILAB Taurus. Fibrinogen was determined by coagulometry using ACL Elite PRO analyzer and leucocyte count was made by flux cytometry with Coulter LH500.

\section{CLINICAL CASE I}

A 58-year-old patient is admitted to the emergency room accusing pain and total functional leg deficit, suddenly instigated by trauma due to an agricultural accident.

The local and general clinical outline reveals: swelling of the right leg, edema, increased consistency, glossy skin, signs of certainty and probability of the fracture, partial sensory and motor deficit in the right leg (Figure 1). The general condition was good without affecting other organs and systems.

Initial emergency treatment was initiated: immobilization of the right lower limb, hydroelectrolytic and volume rebalancing. Blood tests reveal a significant increase in creatine kinase, fibrinogen, LDH and leucocytes levels (Table 1, Figures 2, 3 and 4).

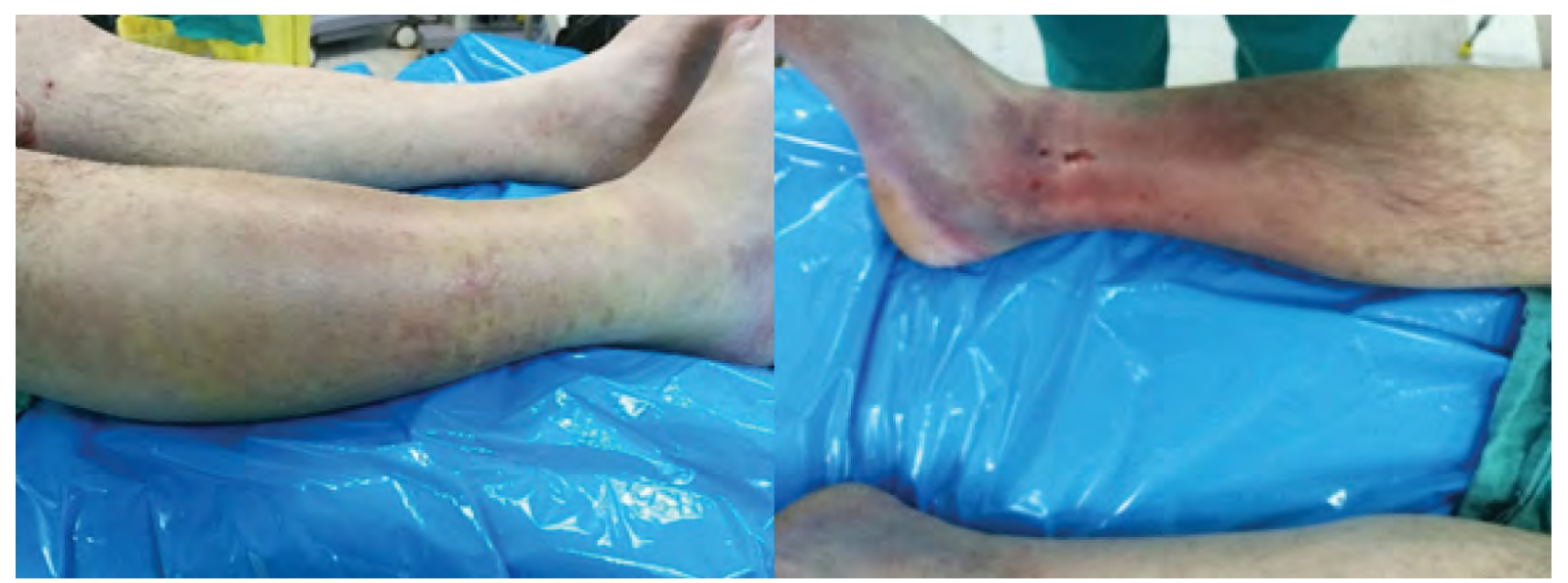

FIGURE 1. Image of a post-traumatic leg with signs that reveal a probable fracture (swelling, edema, increased consistency, glossy skin) 
TABLE 1. Blood test results for clinical case I

\begin{tabular}{|c|c|c|c|c|}
\hline $\begin{array}{c}\text { Time of registration of the } \\
\text { parameters }\end{array}$ & CK & Fibrinogen & LDH & Leukocyte count \\
\hline Before surgical intervention & $1,205 \mathrm{U} / \mathrm{I}$ & $558 \mathrm{mg} / \mathrm{dl}$ & $870 \mathrm{U} / \mathrm{I}$ & $16.2 \times 10^{3} / \mu l$ \\
\hline 2 hours after surgical intervention & $1,184 \mathrm{U} / \mathrm{I}$ & $335 \mathrm{mg} / \mathrm{dl}$ & $534 \mathrm{U} / \mathrm{I}$ & $9.8 \times 10^{3} / \mu \mathrm{l}$ \\
\hline 8 hours after surgical intervention & $935 \mathrm{U} / \mathrm{l}$ & & & \\
\hline 12 hours after surgical intervention & $720 \mathrm{U} / \mathrm{I}$ & & & \\
\hline 24 hours after surgical intervention & $378 \mathrm{U} / \mathrm{I}$ & & & $11.6 \times 10^{3} / \mu \mathrm{l}$ \\
\hline 3 Days after surgical intervention & $192 \mathrm{U} / \mathrm{I}$ & $554 \mathrm{mg} / \mathrm{dl}$ & $534 \mathrm{U} / \mathrm{I}$ & $9.9 \times 10^{3} / \mu \mathrm{l}$ \\
\hline 5 days after surgical intervention & $79 \mathrm{U} / \mathrm{I}$ & $428 \mathrm{mg} / \mathrm{dl}$ & $534 \mathrm{U} / \mathrm{I}$ & $10.0 \times 10^{3} / \mu \mathrm{l}$ \\
\hline 10 days after surgical intervention & $32 \mathrm{U} / \mathrm{I}$ & $591 \mathrm{mg} / \mathrm{dl}$ & & $10.86 \times 10^{3} / \mu \mathrm{l}$ \\
\hline
\end{tabular}

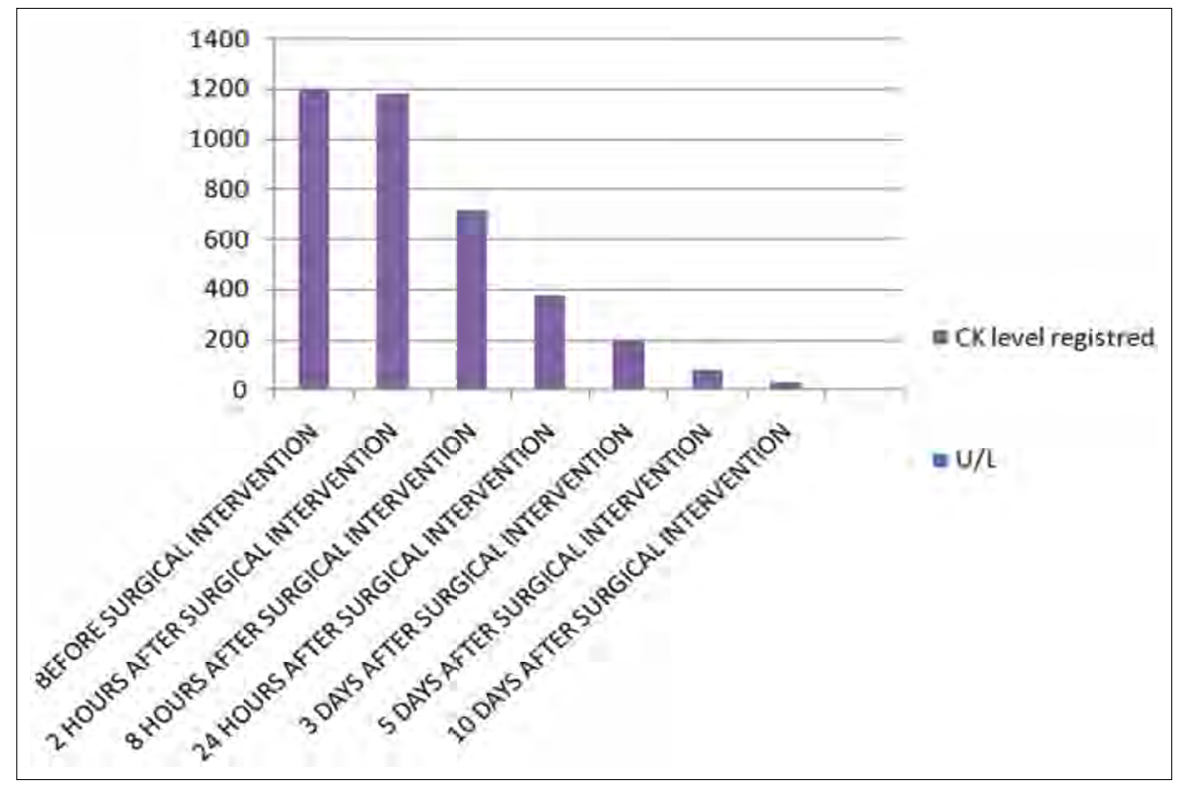

FIGURE 2. Variation of CK level during hospitalization period (clinical case I)

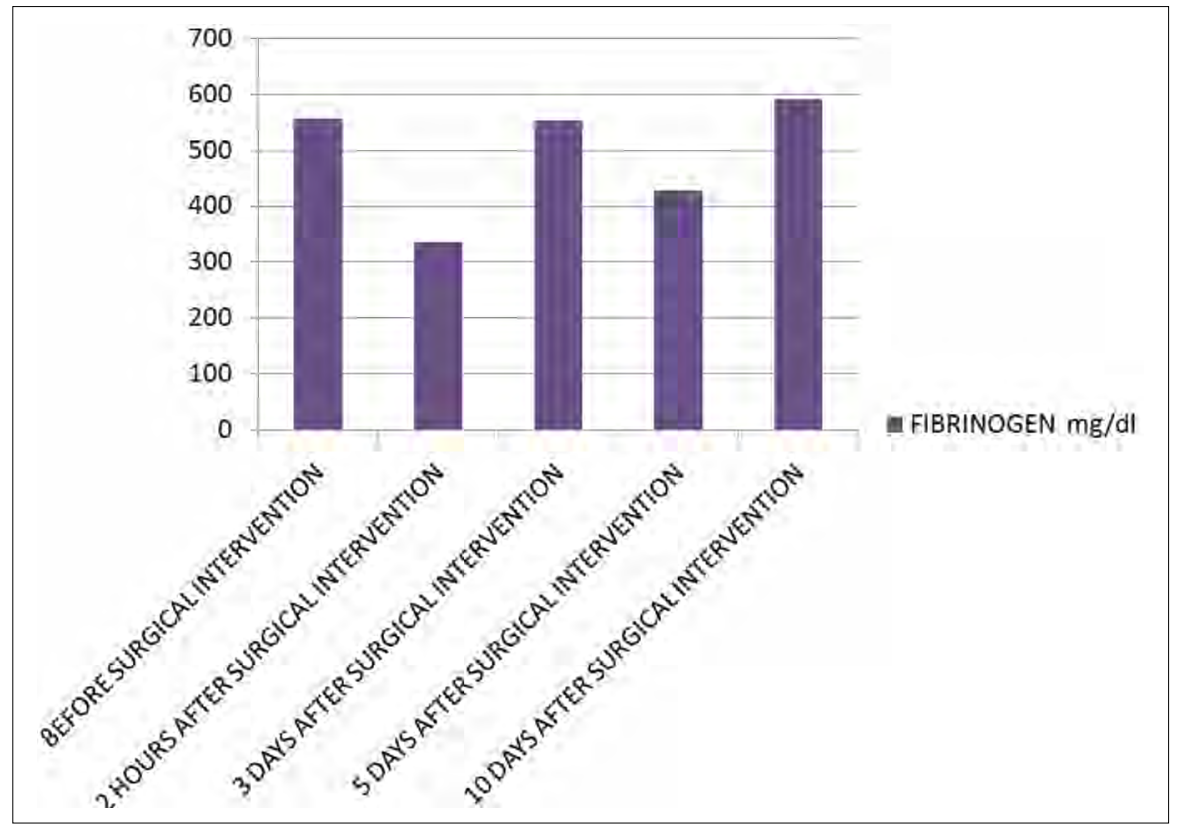

FIGURE 3. Variation of fibrinogen level during hospitalization period (clinical case I) 


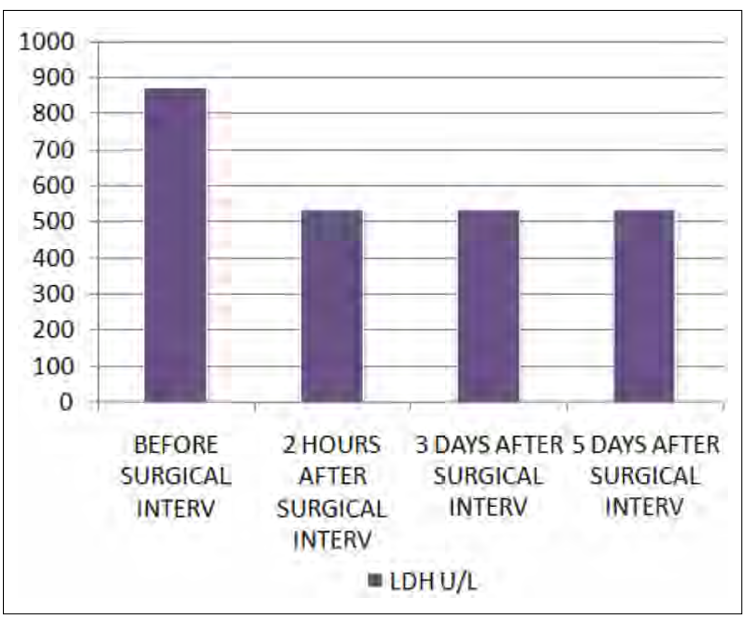

FIGURE 4. Variation of LDH level during hospitalization period (clinical case I)

Following the local clinical examination and determination of increased levels for the biochemical markers with specificity for the presence of associated muscle damage, surgery is performed urgently and, besides the treatment of the fractures (osteosynthesis with external fixator), decompressive fasciotomy is performed.

Intraoperative the presence of acute muscle damage was noticed, marked by the edema of the muscular groups and their herniation at the time of decompression, but their viability both vascular and nervous was present.

After surgery (Figure 5), under local and systemic treatment, local and general evolution is favorable with improvement of local symptomatology and progressive normalization of values of tissue destruction markers.

\section{CLINICAL CASE II}

A 42-year-old patient with trauma from a traffic accident is admitted to the emergency room accusing pain and total functional leg deficit.

The local and general clinical outline reveals: open fracture type IIIB of the distal tibia, swelling of the right leg, edema, signs of certainty and probability of the fracture, distal pulse present (Figure 6). The general condition was good without affecting other organs and systems.

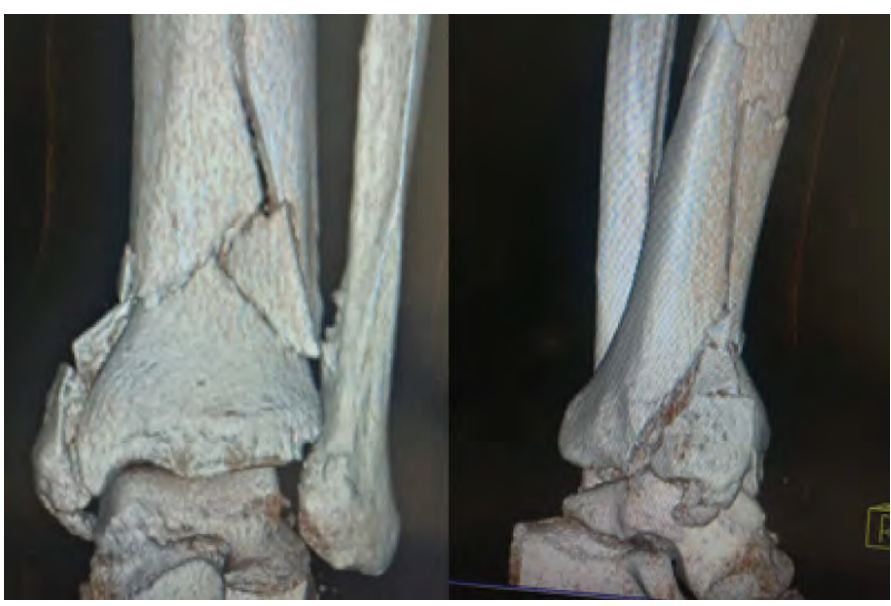

FIGURE 6. CT scan images of open fracture type IIIB of the distal tibia

Initial emergency treatment was initiated: immobilization of the right lower limb, hydroelectrolytic and volume rebalancing. Blood tests revealed a significant increase in creatine kinase, fibrinogen, LDH and leucocytes (Table 2, Figures 7, 8 and 9).

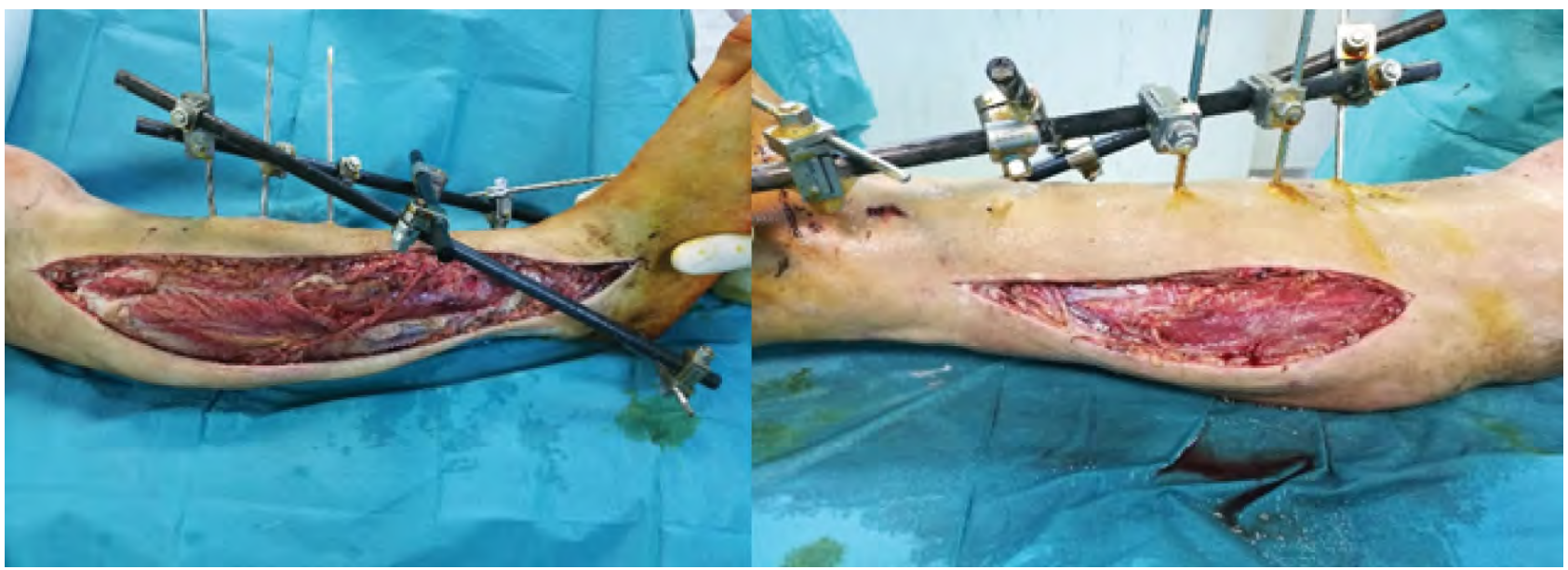

FIGURE 5. Image of the leg after surgical intervention 
TABLE 2. Blood test results in clinical case II

\begin{tabular}{l|c|c|c|c}
\hline Time of registration of the parameters & CK & Fibrinogen & LDH & Leukocyte count \\
\hline Before surgical intervention & $1978 \mathrm{U} / \mathrm{l}$ & $778 \mathrm{mg} / \mathrm{dl}$ & $1,025 \mathrm{U} / \mathrm{I}$ & $7.27 \times 10^{3} / \mu \mathrm{l}$ \\
\hline 2 hours after surgical intervention & $1884 \mathrm{U} / \mathrm{l}$ & $735 \mathrm{mg} / \mathrm{dl}$ & $934 \mathrm{U} / \mathrm{l}$ & $9.8 \times 10^{3} / \mu \mathrm{l}$ \\
\hline $\mathbf{8}$ hours after surgical intervention & $1035 \mathrm{U} / \mathrm{l}$ & & & \\
\hline 12 hours after surgical intervention & $920 \mathrm{U} / \mathrm{l}$ & & & \\
\hline $\mathbf{2 4}$ hours after surgical intervention & $918 \mathrm{U} / \mathrm{l}$ & & & $9.6 \times 10^{3} / \mu \mathrm{l}$ \\
\hline $\mathbf{3}$ days after surgical intervention & $432 \mathrm{U} / \mathrm{l}$ & $634 \mathrm{mg} / \mathrm{dl}$ & $534 \mathrm{U} / \mathrm{l}$ & $9.9 \times 10^{3} / \mu \mathrm{l}$ \\
\hline $\mathbf{5}$ days after surgical intervention & $379 \mathrm{U} / \mathrm{l}$ & $548 \mathrm{mg} / \mathrm{dl}$ & $359 \mathrm{U} / \mathrm{l}$ & $8.0 \times 10^{3} / \mu \mathrm{l}$ \\
\hline 10 days after surgical intervention & $64 \mathrm{U} / \mathrm{l}$ & $481 \mathrm{mg} / \mathrm{dl}$ & & $7.87 \times 10^{3} / \mu \mathrm{l}$ \\
\hline
\end{tabular}

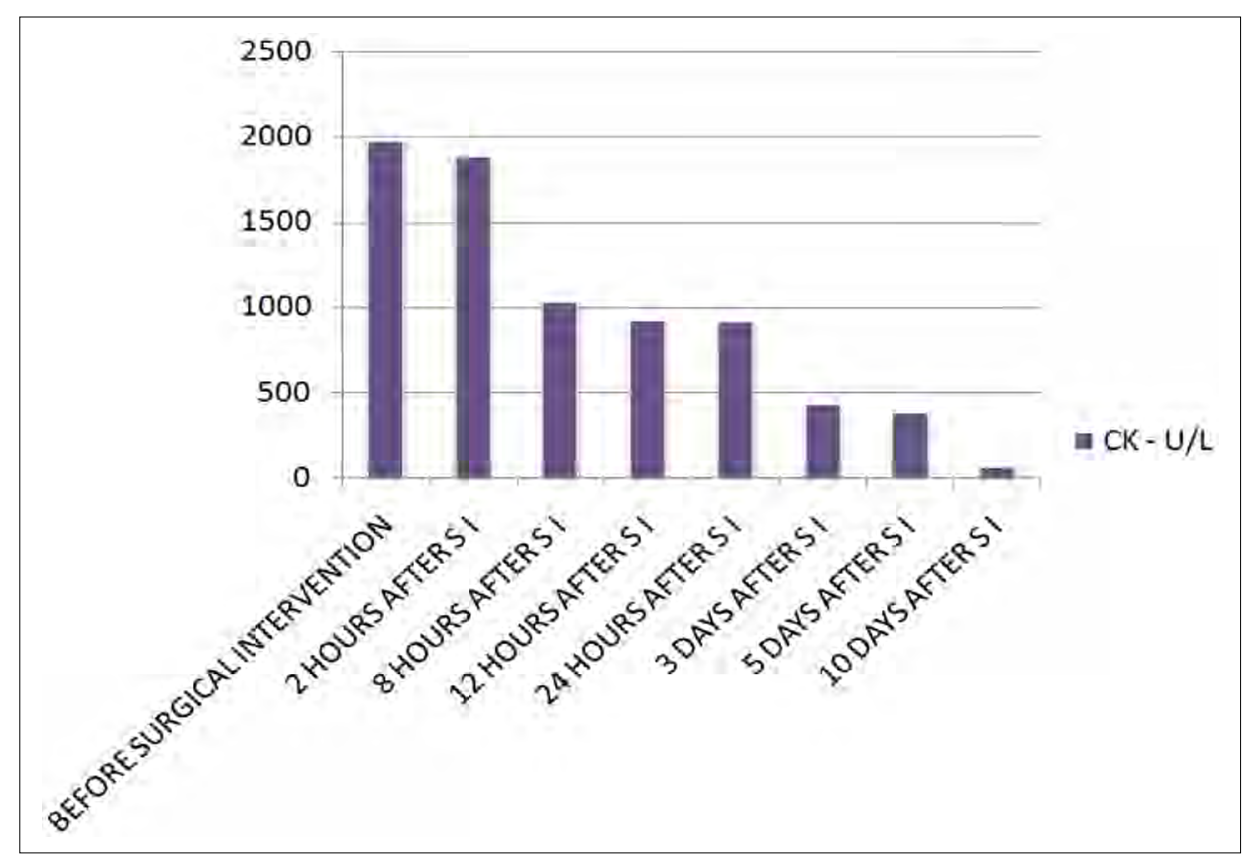

FIGURE 7. Variation of CK level during hospitalization period (clinical case II)

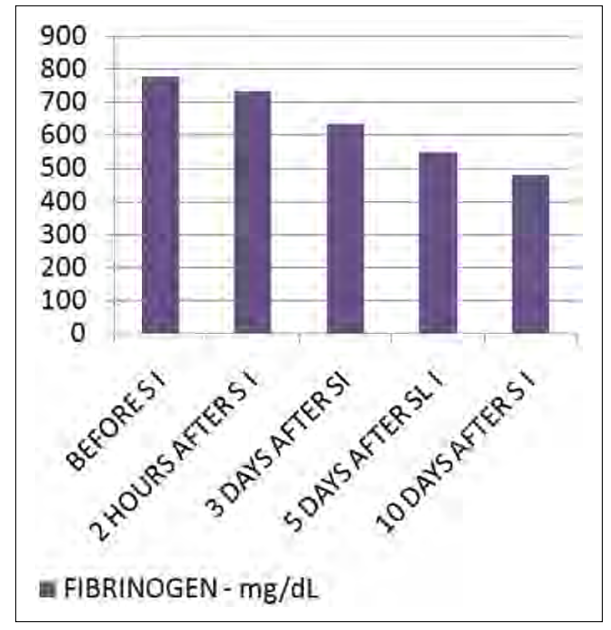

FIGURE 8. Variation of fibrinogen level during hospitalization period (clinical case II)

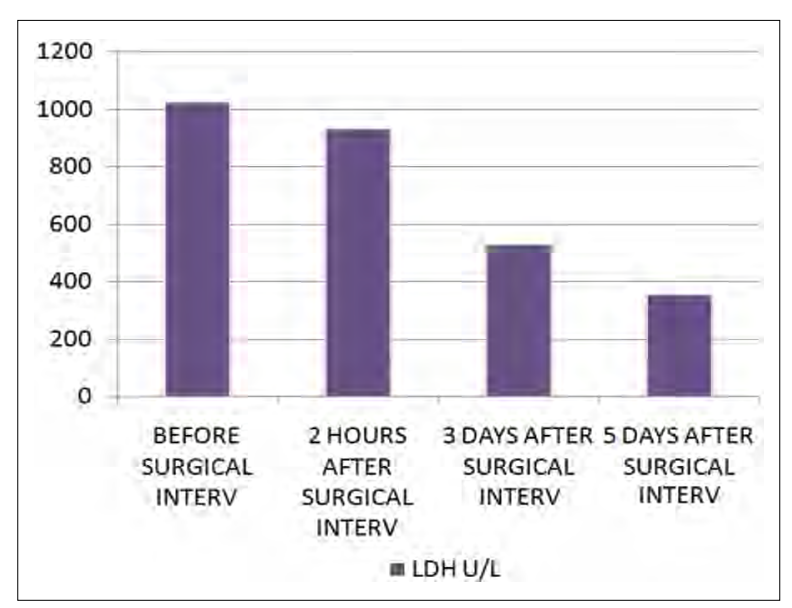

FIGURE 9. Variation of $L D H$ level during hospitalization period (clinical case II) 
The patient is intubated and mechanical ventilated and surgery is performed urgently (external fixation and decompressive fasciotomy).

After surgical intervention under local and systemic treatment, local and general evolution is favorable with improvement of the local symptomatology and with progressive normalization of values of tissue destruction markers.

\section{CLINICAL CASE III}

A 91-year-old patient who had a road traffic accident is admitted to the emergency room accusing pain and total functional deficit of the femur and the knee.

The local and general clinical outline reveals: closed fracture of the distal femur, swelling, edema, signs of certainty and probability of the fracture, distal pulse present (Figure 10).

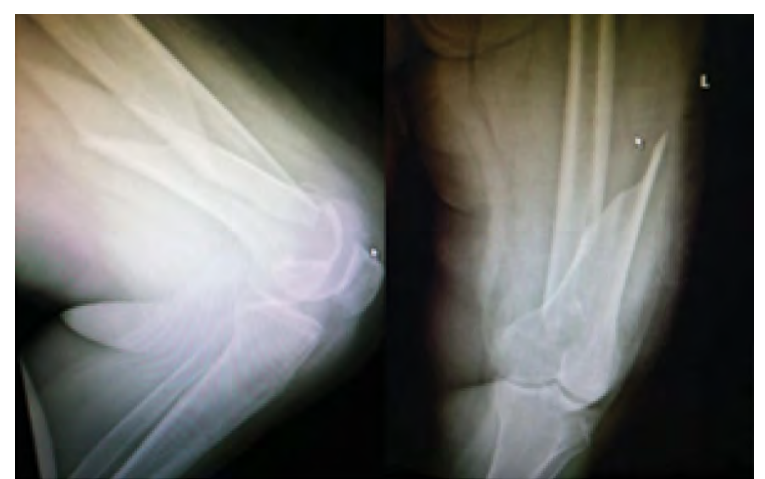

FIGURE 10. Femur fracture

The associated pathology included unique surgical kidney, severe heart failure and severe hypertension. Initial emergency treatment is initiated: hydroelectrolytic and volume rebalancing. Blood tests reveal a significant increase in creatine kinase, fibrinogen, LDH and leucocytes (Table 3, Figures 11, 12 and 13).

TABLE 3. Blood test results in clinical case III

\begin{tabular}{l|c|c|c|c}
\hline Time of registration of the parameters & CK & Fibrinogen & LDH & Leukocyte count \\
\hline Before surgical intervention & $2301 \mathrm{U} / \mathrm{l}$ & $539 \mathrm{mg} / \mathrm{dl}$ & $464 \mathrm{U} / \mathrm{I}$ & $16.29 \times 10^{3} / \mu \mathrm{l}$ \\
\hline 2 hours after surgical intervention & $2276 \mathrm{U} / \mathrm{I}$ & $778 \mathrm{mg} / \mathrm{dl}$ & $663 \mathrm{U} / \mathrm{I}$ & $12.7 \times 10^{3} / \mu \mathrm{l}$ \\
\hline $\mathbf{8}$ hours after surgical intervention & $2276 \mathrm{U} / \mathrm{I}$ & $682 \mathrm{mg} / \mathrm{dl}$ & $928 \mathrm{U} / \mathrm{I}$ & $13.7 \times 10^{3} / \mu \mathrm{l}$ \\
\hline 12 hours after surgical intervention & $802 \mathrm{U} / \mathrm{I}$ & $634 \mathrm{mg} / \mathrm{dl}$ & $842 \mathrm{U} / \mathrm{I}$ & $14.27 \times 10^{3} / \mu \mathrm{l}$ \\
\hline $\mathbf{2 4}$ hours after surgical intervention & $578 \mathrm{U} / \mathrm{I}$ & $458 \mathrm{mg} / \mathrm{dl}$ & $896 \mathrm{U} / \mathrm{I}$ & $10.7 \times 10^{3} / \mu \mathrm{l}$ \\
\hline $\mathbf{3}$ days after surgical intervention & $432 \mathrm{U} / \mathrm{I}$ & $434 \mathrm{mg} / \mathrm{dl}$ & $812 \mathrm{U} / \mathrm{I}$ & $9.7 \times 10^{3} / \mu \mathrm{l}$ \\
\hline $\mathbf{5}$ days after surgical intervention & $167 \mathrm{U} / \mathrm{I}$ & $3484 \mathrm{mg} / \mathrm{dl}$ & $741 \mathrm{U} / \mathrm{I}$ & $8.7 \times 10^{3} / \mu \mathrm{l}$ \\
\hline 10 days after surgical intervention & $146 \mathrm{U} / \mathrm{I}$ & $287 \mathrm{mg} / \mathrm{dl}$ & $985 \mathrm{U} / \mathrm{I}$ & $6.87 \times 10^{3} / \mu \mathrm{l}$ \\
\hline
\end{tabular}

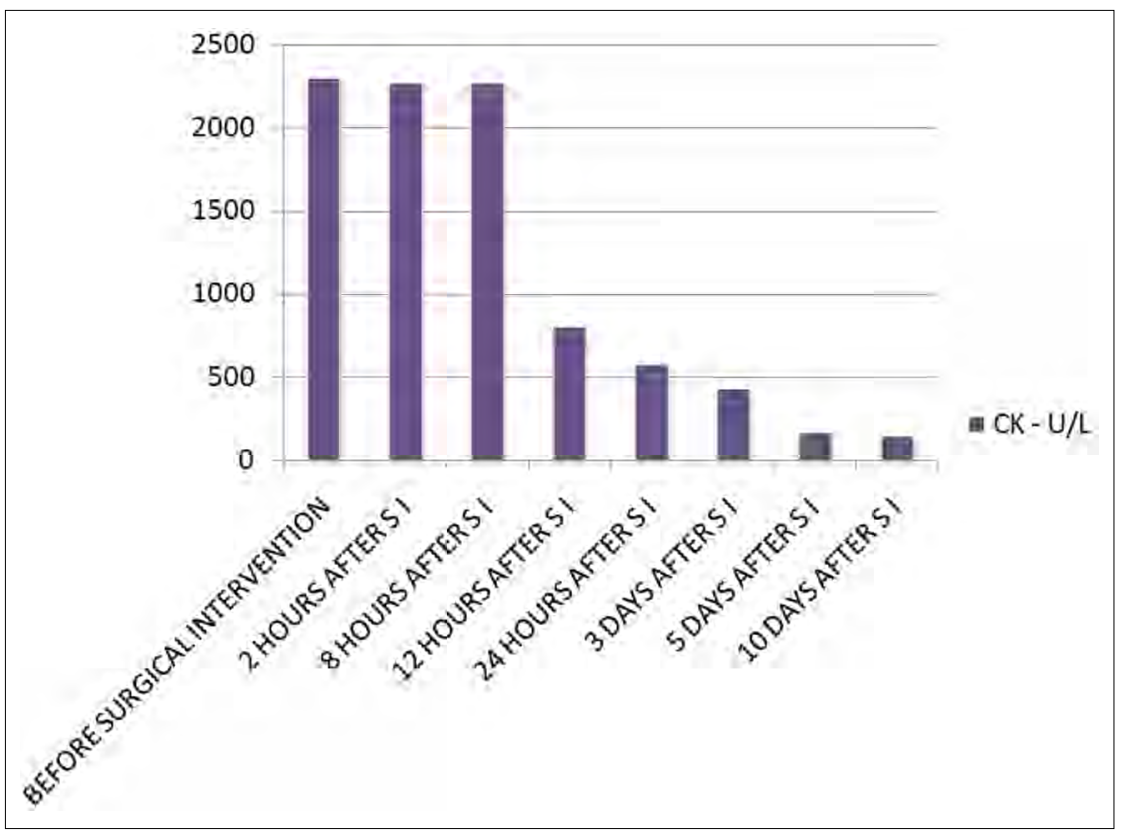

FIGURE 11. Variation of CK level during hospitalization period (clinical case III) 


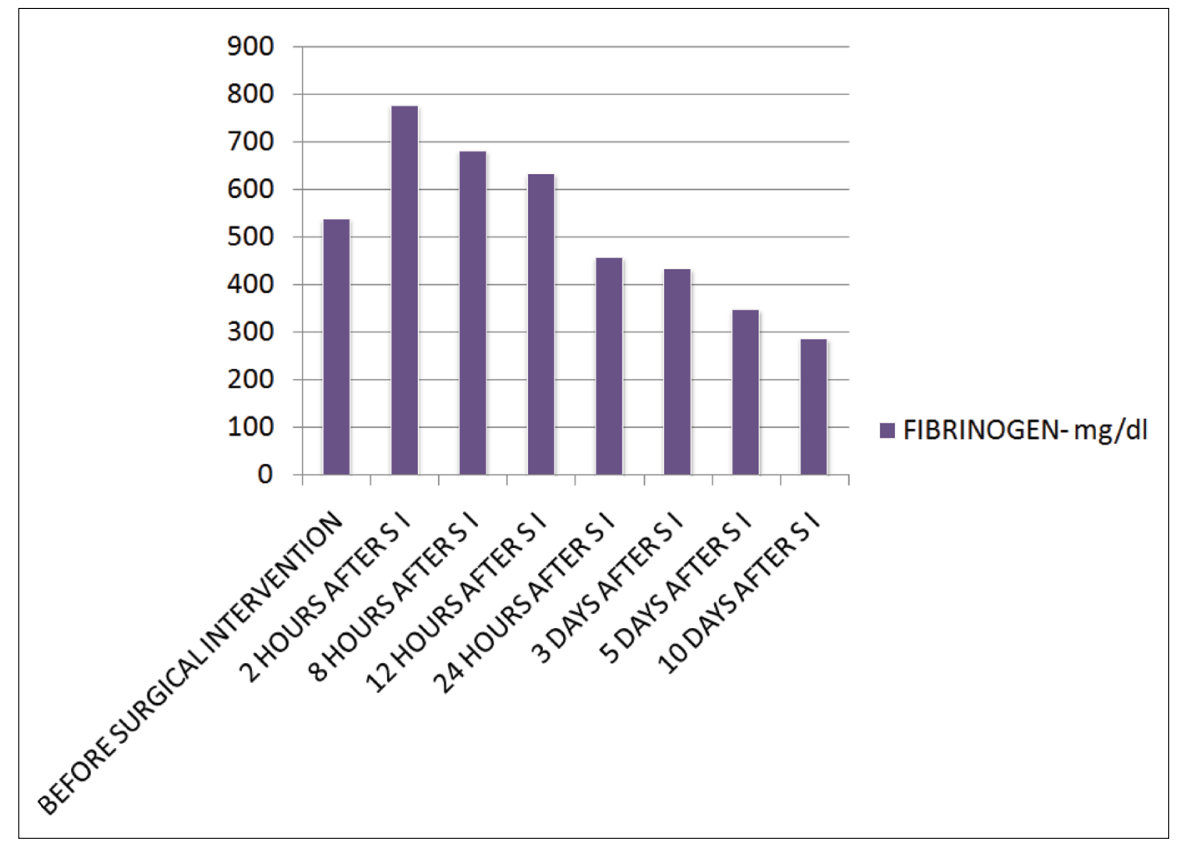

FIGURE 12. Variation of fibrinogen level during hospitalization period (clinical case III)

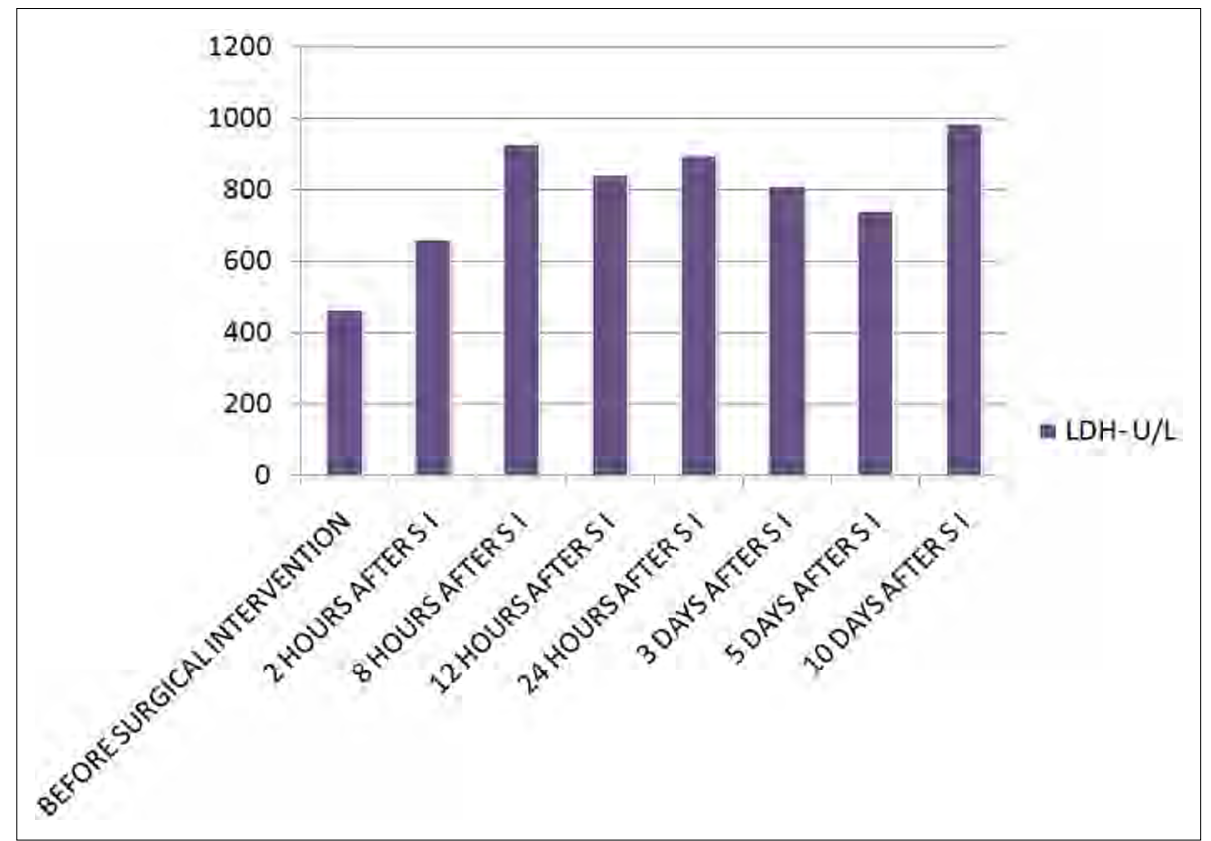

FIGURE 13. Variation of LDH level during hospitalization period (clinical case III)

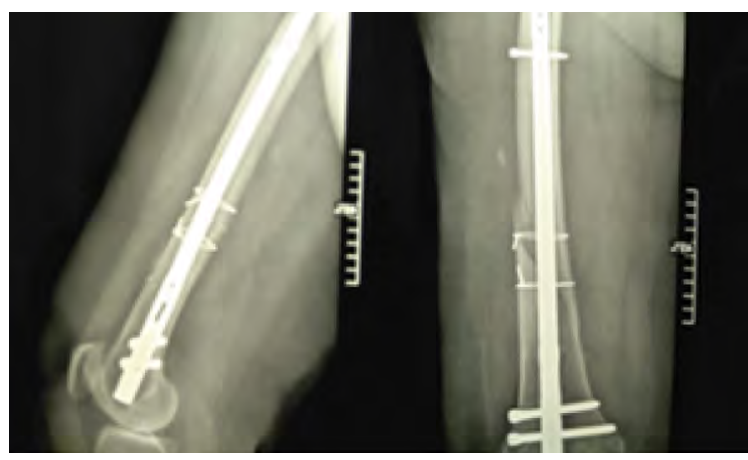

FIGURE 14. Internal fixation with intramedulary nail
The patient is intubated and mechanically ventilated and surgery is performed urgently, consisting of closed reduction and internal fixation with intramedulary nail (Figure 14).

After surgical intervention under local and systemic treatment, local and general evolution is stationary, but after 3 hours the general status gets worse due to the decompensation of the associated pathologies. Despite the efforts made, the patient's condition got worse and 14 days after the surgery exitus was declared. 


\section{DISCUSSIONS}

In crush syndrome muscle tissue injury is characterized by sarcomeric degeneration from Z-disk fragmentation [5]. Normally, muscle cell architecture allows to minimize the stress targeted on the plasma membrane by channeling the forces from extracellular matrix to the cytoskeleton through the dystrophin-glycoprotein complex [5]. In crush injuries, membrane failure results in the loss of cytoplasmic components (like enzymes) and allows the influx of extracellular ions. The increase in serum levels of such enzymes should be a valuable index of cellular necrosis or tissue damage following muscle crush injuries $[5,6]$.

As a consequence of muscular cell death increased level of myoglobin and creatine kinase levels five times above the upper limit of normal level $(>1,000 \mathrm{U} / \mathrm{I})$ are being registered in patients with CS. Normal CK enzyme levels are 45-260 U/l. CK levels rise in rhabdomyolysis within 12 hours, increase in the hours following muscle damage and remain elevated for several days. The half-life of CK is 1.5 days and so it remains elevated longer than serum myoglobin levels that has a short halflife (2-3 hours). Estimation of myoglobin in serum and urine is useful, particularly in the early phases of the disease. CK is easily assessed in the serum and is a sensitive, but not specific, marker of muscle tissue damage due to its isoforms distribution (skeletal muscles, myocardium, brain and kidney).

Depending on the mechanical or metabolic causes of which the muscle tissue was damaged, the biological status is altered.

In this context, the levels of skeletal muscle enzymes and proteins determined in serum of this kind of patients represent valuable markers of muscle tissue functional status. These biochemical markers could vary greatly when they are recorded under different pathological conditions that appear in the case of muscle tissue damage. In current practice, the most useful serum markers are: $\mathrm{CK}, \mathrm{LDH}$ and other markers of inflammation like fibrinogen and leucocytes count.

In studies conducted by Brancaccio and colleagues, ALD and carbonic anhydrase CAlll should be considered as valuable biomarkers for the evaluation of muscle damage although currently, serum $\mathrm{CK}$ is considered the most sensitive indicator of the evaluation of muscle crush injuries. Other markers that reveal the functional status of muscle tissue, beside creatine kinase and lactate dehydrogenase could be aldolase, myoglobin, troponin, aspartate aminotransferase, and carbonic anhydrase CAIII that are also useful serum markers of muscle injury [5-8].

Recent studies have reported individual clinical cases of patients with fasciitis $[9,10]$ who had normal CK levels, but high serum ALD levels. Moreover, two researchers described clinical cases in which some patients had selectively elevated ALD serum levels $[6,11]$.

\section{CONCLUSIONS}

The analysis of biochemical markers in dynamics highlights the relatively high specificity of $\mathrm{CK}$ and $\mathrm{LDH}$, the decrease in their levels being directly proportional to the local and general clinical evolution. Regarding fibrinogen, its levels decrease initially, then return close to the initial value, even exceeding it, leading us to consider this investigation less specific.

Although the local and general evolution following the rapid and accurate diagnosis of the crush syndrome associated with fracture of the tibia was favorable, with the reduction of local and general complications, the period of hospitalization was very long, the patient required numerous surgeries for closing and curing the skin lesions (the patient required plaster grafting) and for achieving definitive osteosynthesis.

The particularity of the case is represented by the association of the basic pathology (the tibia and peroneal fracture) with the crush syndrome. This association greatly complicates local and general treatment, requiring a different therapeutic approach (surgical and medical), prolongs the period of hospitalization and related costs.

Cytosolic proteins (CK, LDH, myoglobin) have a relatively limited response to muscle damage. Monitoring them in dynamics gives an overview of the degree of muscle destruction, but the lack of specificity can make it difficult to diagnose quickly and initiate treatment.

\section{Acknowledgement}

All authors equally contributed to the present paper.

Conflict of interest: none declared Financial support: none declared 


\section{REFERENCES}

1. Xu ZQ, Shao BZ, Ke P et al. Combined administration of anisodamine and neostigmine rescued acute lethal crush syndrome through $\alpha 7 \mathrm{nAChRdependent}$ JAK2-STAT3 signaling. Scientific Reports, 2016; 6:37709.

2. Greaves I, Porter K, Smith JE. Consensus statement on the early management of crush injury and prevention of crush syndrome. J R Army Med Corps., 2003; 149(4):255-259.

3. Aoki N, Demsar J, Zupan B et al. Predictive Model for Estimating Risk of Crush Syndrome: A Data Mining Approach. J Trauma, 2007; 62:940-945.

4. Keltz E, Khan FJ, Mann G.

Rhabdomyolysis. The role of diagnostic and prognostic factors. Muscles, Ligaments and Tendons Journal. 2013; 3(4):303-312.

5. Brancaccio P, Lippi G, Maffulli N.

Biochemical markers of muscular damage. Clin Chem Lab Med., 2010; 48(6):757-767.

6. Creanga I, Totan A, Lupescu et al. Aldolase - From Biochemistry to Laboratory Medicine, Rev. chim (Bucharest), 2019; 70 (2):578-580.

7. Casciola-Rosen L, Hall JC, Mammen AL et al. Isolated elevation of aldolase in the serum of myositis patients: A potential biomarker of damaged early regenerating muscle cells. Clin. Exp. Rheumatol, 2012; 30(4):548-553.

8. Casciola-Rosen L, Nagaraju K, Plotz P et al. Enhanced autoantigen expression in regenerating muscle cells in idiopathic inflammatory myopathy. J Exp Med., 2005; 201:591-601.

9. Fujimoto M, Sato $\mathrm{S}$, Ihn H et al. Serum aldolase level is a useful indicator of disease activity in eosinophilic fasciitis. Rheumatol, 1995; 22:563-565.

10. Quintero-Del-Rio Al, Punaro M, Pascual V. Faces of eosinophilic fasciitis in childhood. J ClinRheumatol, 2002; 8:99-103.

11. Nozaki K, Pestronk A. High aldolase with normal creatine kinase in serum predicts a myopathy with perimysial pathology. J. Neurol. Neurosurg. Psychiatry, 2009; 80:904-908. 